\title{
Contrast agents for MRI: 30+ years and where are we going?
}

\author{
Valérie C. Pierre • Matthew J. Allen • \\ Peter Caravan
}

Received: 13 September 2013/Accepted: 8 December 2013/Published online: 11 January 2014

(C) SBIC 2014

\begin{abstract}
Thirty years ago, Schering filed the first patent application for a contrast agent for magnetic resonance imaging (MRI) covering the forefather of the gadolinium contrast agents and still the most widely used gadolinium probe: gadolinium(III) diethylenetriaminepentaacetate (Magnevist). To date, 11 contrast agents have been approved by the US Food and Drug Administration for intravenous use. Coordination chemists have done a great deal to move the field forward. Our understanding of lanthanide chemistry now makes possible the design of complexes with long rotational correlation times, fast or slow water-exchange rates, high thermodynamic stabilities, and kinetic inertness, leading to sensitive and nontoxic contrast agents. Chemists did not stop there. The last few decades has seen the development of novel classes of probes that yield contrast through different mechanisms, such as paramagnetic chemical exchange saturation transfer agents. Thirty years since the first patent, chemists are still leading the way. The development of high-sensitivity
\end{abstract}

Responsible Editor: Valerie C. Pierre.

V. C. Pierre $(\bowtie)$

Department of Chemistry, University of Minnesota,

Minneapolis, MN 55455, USA

e-mail: pierre@umn.edu

M. J. Allen ( $\square)$

Department of Chemistry, Wayne State University, Detroit, MI 48202, USA

e-mail: mallen@chem.wayne.edu

P. Caravan $(\bowtie)$

Department of Radiology, A. A. Martinos Center for Biomedical Imaging, Massachusetts General Hospital, Harvard Medical

School, Charlestown, MA 02129, USA

e-mail: caravan@nmr.mgh.harvard.edu contrast agents for high magnetic fields, safe probes for patients with kidney disorders, and multimodal, targeted, and responsive agents demonstrates that the field of contrast agents for MRI still has much to offer.

Keywords Magnetic resonance imaging - Contrast agents $\cdot$ Gadolinium $\cdot$ Lanthanides

"What happened to all the promises?" This question was first asked to one of us on starting our independent career. It was asked by one of the most prominent members of our field, one of the founders of functional magnetic resonance imaging (MRI) and high-field MRI. He had believed in contrast agents. He had looked forward to using responsive contrast agents with high sensitivity at high magnetic field strengths, but as 15 years passed and these powerful ideas had not yet been translated into clinical medicine and everyday biomedical research, he and much of the field of MRI moved on from contrast agents. Of the 4,575 abstracts of the 2013 meeting of the International Society for Magnetic Resonance in Medicine, fewer than $15 \%$ contained the term "contrast agent." What happened? Where is the field of contrast agents going? What is the place of chemists in this trek? This commentary is not a review. It does not provide answers to these questions either. It represents our current opinion, and is meant to open a dialog.

It all started about 30 years ago. The forefather of the gadolinium contrast agents, gadolinium(III) diethylenetriaminepentaacetate (Gd-DTPA; Magnevist), was first described as a contrast agent in 1981 [1, 2]. By 1983, the first report of an animal study using Gd-DTPA as an NMR contrast agent was published [3]. A year later, Schering filed the first patent application on an MRI contrast agent. The first claim of US patent $4,647,447$ was broad to say the 
least; it protected every "diagnostic medium [which] comprises a physiologically compatible salt of (a) an anion of a complexing acid and (b) at least one central ion of an element with an atomic number of 21 to $29,42,44$ or 57 to 83 chelated therewith" [4]. In 1988, Magnevist received US Food and Drug Administration (FDA) approval in the USA for contrast-enhanced MRI of the central nervous system; this approval was extended in 1993 to the rest of the body except for the heart. The field of MRI contrast agents was born.

In the 15 years after the FDA approval of Magnevist, three other extracellular fluid contrast agents would receive FDA approval: ProHance (gadoteridol) in 1992, Omniscan (gadodiamide) in 1993, and Optimark (gadoversetamide) in 1999. Additionally, five other contrast agents (three for extracellular fluid, one for hepatobiliary imaging, and one blood pool agent) that were initially reported in this timeframe have since been approved: MultiHance (gadobenate dimeglumine) in 2004, Eovist (gadoxetate) in 2008, Ablavar (formerly Vasovist and MS-325; gadofoveset) in 2008, Gadavist (gadobutrol) in 2011, and Dotarem (Gd-DOTA) in 2013. Many of these, such as Gd-DOTA, had been approved much earlier in Europe and other countries. Only two non-gadolinium-based contrast agents have been approved for intravenous use by the FDA: Feridex (dextran-coated iron oxide nanoparticles) and Teslascan (mangafodipir) were approved by the FDA for the evaluation of lesions of the liver in 1996 and 1997. Neither of these is commercially available anymore owing to poor sales. To this day, all extracellular fluid and blood pool contrast agents approved by the FDA are gadoliniumbased. By the end of 2009, gadolinium-based contrast agents had been administered an estimated 87.5 million times in the USA alone, with most administrations (more than 50 million) using the original Gd-DTPA [5].

It was quickly discovered that the toxicity of these agents is linked not only to their thermodynamic instability, but also to their kinetic lability with respect to metal dissociation, ligand exchange, and transmetallation [6-9]. The problem of gadolinium release would haunt the field with the first cases of nephrogenic systemic fibrosis (NSF) reported in 2006 in patients with chronic or acute severe renal insufficiency and who had received a gadoliniumbased contrast agent [10]. Gadolinium was found in the skin and internal organs of those patients, leading to an association of gadolinium with this rare, but devastating, disease [11]. There also appeared to be a correlation between the prevalence of NSF and the type of contrast agent used, with more kinetically labile and less thermodynamically stable complexes resulting in more cases of the disease [12, 13]. In 2007, the occurence of NSF symptoms resulted in the requirement for a black box warning in the labels of gadolinium-based contrast agents.
In 2010, this warning was revised to explicitly contraindicate the use of Gd-DTPA, gadodiamide, and gadoversetamide in patients with chronic severe kidney disease [14]. Today, the incidence of NSF is extremely low because of prescreening of patients for renal dysfunction [15]. The interplay between NSF and fundamental coordination chemistry demonstrates the need for chemists to be involved in the field.

The effectiveness of a contrast agent, given by its longitudinal and transverse relaxivities, is another area where chemistry plays an important role. The sensitivity of clinical agents remains a problem although the optimization of gadolinium-based contrast agents began immediately after their initial reports. The recommended dose for gadolinium-based contrast agents, typically $0.1-0.3 \mathrm{mmol} \mathrm{kg}^{-1}$, requires the injection of gram quantities of drugs for standard clinical applications. Researchers swiftly turned to relaxation theory developed by Solomon, Bloembergen, and Morgan [16-19] to rationally improve gadolinium-based contrast agents. For low molecular weight complexes such as Gd-DTPA, the relaxivity is limited by the fast molecular tumbling. The first step in improving the relaxivity of these contrast agents thus involved slowing down the tumbling with macromolecular complexes. As early as 1985, Lauffer et al. $[20,21]$ demonstrated that conjugating a gadolinium complex to a protein reduces its tumbling rate, which leads to a tremendous increase in relaxivity. When the tumbling rate is slowed, however, another parameter becomes limiting: the water-exchange rate. In the 1980s, it was assumed, on the basis of the fast kinetics observed for the aqua complex $\left(10^{9} \mathrm{~s}^{-1}\right.$ [22]) that the water-exchange rate at $\mathrm{Gd}(\mathrm{III})$ was universally fast. Despite these early expectations, the lability of the inner-sphere water molecules is substantially impacted by chelate structure. Clinical gadolinium-based contrast agents have waterexchange rates in the range of $10^{6}-10^{7} \mathrm{~s}^{-1}$ [23], far too slow to optimize the relaxivity of macromolecular complexes [24-26]. Since those early reports, complexes with fast water-exchange kinetics have been reported that do not limit the relaxivity of macromolecular derivatives [27-29]. These new complexes include the hydroxypyridone family of complexes [30], phosphonic acid derivatives of dodecanetetraacetic acid [31], and the extended diethylenetriaminepentaacetate analog ethylenepropylenetriaminepentaacetate [32].

This fundamental coordination chemistry research also identified ligands that impart complexes with slow waterexchange kinetics, such as the tetraamide derivatives of dodecanetetraacetic acid [33]. Although such ligands were not suitable for gadolinium-based contrast agents, Sherry et al. [34] and Aime et al. [35] recognized that when $\mathrm{Gd}(\mathrm{III})$ was replaced with another paramagnetic 
lanthanide, the resulting complexes could generate contrast through the paramagnetic chemical exchange saturation transfer (PARACEST) mechanism.

As we look at the work accomplished over the last 30 years, and the lessons learned from these studies, we believe that the field of contrast agents for MRI is by no means declining. As with the rest of the pharmaceutical field, a substantial amount of time and money is needed to move a contrast agent from the bench to the bedside. Although the length of time required for new contrast agents to become clinically approved is long, the success rate is encouraging: the fact that there are ten approved agents from 130 listed in the Molecular Imaging and Contrast Agent Database [36] indicates that the percentage of approved agents is relatively high compared with the roughly one in 5,000 therapeutics that make it to the market [37]. We might not have fulfilled all the promises yet, and these promises may not be fulfilled as we initially envisioned, but the potential remains. As the reviews and research articles in this special issue attest, much innovative and promising research is ongoing. The imagination of contrast-agent chemists should not be underestimated. The following are some of the most significant areas of current research:

- High-relaxivity gadolinium complexes The clinical need for extracellular fluid contrast agents, and perhaps even blood pool contrast agents is likely fulfilled. This does not mean that the poor sensitivity of these agents has been resolved. Detection of gadolinium-based contrast agents at local concentrations in the micromolar range in vivo remains elusive. Hence, a continuing research area of interest for chemists remains the development of contrast agents with high relaxivity (greater than $100 \mathrm{mM}^{-1} \mathrm{~s}^{-1}$ per $\mathrm{Gd}^{3+}$ ion) at high to ultrahigh magnetic field strengths (3-16.4 T). The efficacy of targeted and responsive contrast agents (see below) still depends on this. The road to highrelaxivity gadolinium contrast agents will likely involve macromolecular complexes. In this issue, two novel approaches to rapidly achieving macromolecular size are presented. Botta et al. [38] describe a new ditopic functionalized gadolinium complex for rapid preparation of supramolecular assemblies, and the Helm group [39] proposes self-aggregating complexes as a way to slow rotational correlation rates.

- Non-gadolinium-based contrast agents The route to high sensitivity might not involve gadolinium complexes. Recent research on europium complexes shows their promise as ${ }^{1} \mathrm{H} T_{1}$-shortening contrast agents [40]. PARACEST agents have also shown promise as a new approach to imaging protons. As for the optimization of gadolinium complexes, this is a field in which coordination chemists can make an impact. In this issue, Sherry et al. [41] and Woods et al. [42] discuss the effects of stereochemistry and regioisomerism of PARACEST complexes on water-exchange rates and sensitivity. PARACEST agents need not necessarily incorporate lanthanide ions. Morrow et al. [43] review the use of transition metals as PARACEST agents. Multiplex detection is another promising aspect of PARACEST agents not offered with gadolinium-based contrast agents; Aime et al. [44] describe the design of such an agent and evaluate its potential. PARACEST agents are not the only new class of contrast agents. Fluorinated probes and ${ }^{19} \mathrm{~F}$ MRI have been reported for some time, but the field jumped forward with the recent development of more sensitive lanthanide-based fluorine probes with increased sensitivity. Parker et al. [45] describe glycol chitosan conjugates of paramagnetic fluorine probes for tumor imaging in vivo.

- Safe contrast agents for patients with chronic kidney disorders New contrast agents are needed for patients who cannot use gadolinium-based agents because of chronic kidney disorders, which increase the susceptibility for NSF. Chemistry will likely be important in solving this problem. Some options currently evaluated include iron oxide nanoparticles as well as molecular iron and manganese complexes, such as the manganese porphyrin complexes reported by Zhang et al. [46] and Douglas et al. [47].

- Multimodal agents Multimodal agents that enhance contrast in two or more imaging modalities are promising because different modalities are complementary in terms of spatial resolution, three-dimensional imaging capabilities, depth penetration, and sensitivity. An increasing number of articles are reporting on contrast agents, particularly nanoparticles, with impact on multiple modalities, although far fewer reports exist on their in vivo application relative to in vitro studies. As for macromolecular agents, care should be taken in how these multimodal probes are designed and synthesized to maximize the efficacy of each component [48]. In this issue, Louie et al. [49] present an example of dual positron emission tomography and MRI contrast agents specifically designed to target macrophages.

- Targeted delivery Targeted agents are not limited to the extracellular fluid or the blood. They can be intended to image specific tissues or known disease markers. A variety of strategies enables specific delivery in vivo, including conjugation of targeting molecules and coopting of biological systems. As for every in vivo application, biological barriers such as the blood-brain barrier and the toxicity of the contrast agent also need to be considered. Three different approaches for 
targeted delivery are highlighted in this issue: Yang et al. [50] propose protein-based biomarkers targeting liver tumors; Sherry, Mason et al. [51] report a small gadolinium complex that naturally accumulates in hypoxic tumors; and Tóth et al. [52] use targeting moieties for imaging $\beta$-amyloid plaques.

- Responsive contrast agents Responsive contrast agents are probes whose signal varies as a function of the presence of biomarkers such as small molecules, metal ions, proteins, enzymes, or $\mathrm{pH}$ changes. Their power lies in reporting physiological processes and markers characteristic of diseases. For relaxation agents, signal enhancement depends on both relaxivity (responsive) and concentration. Understanding the relative contributions of relaxivity and concentration is a problem that needs to be addressed for practical in vivo application. Ratiometric probes which can distinguish between increased signal intensity due to the presence of the targeted biomarker versus higher local concentration of contrast agent are needed. Newer types of agents, including PARACEST, ${ }^{19} \mathrm{~F}$, and $\mathrm{Eu}(\mathrm{II})$ agents, offer potential alternatives to gadolinium-based agents for overcoming these limitations. The answer will likely be a combination of different approaches (chemistry, physics, biology, and radiology).

The articles and reviews presented in this issue offer a glimpse of ongoing research in the field of MRI contrast agents and of the diversity of approaches taken to design contrast agents of higher sensitivity and lower toxicity. New probes that make possible imaging of specific tissues or diseases are constantly being developed. Responsive agents making possible direct monitoring of physiological events for biomedical research remain within reach. The field is more than ever multidisciplinary; many groups collaborate, and chemists and radiologists often join forces. Not all the promises may have been met, but there is much power in contrast agents yet to be unleashed, and the diversity and potential of the field is ever increasing. Although it is tempting to focus solely on contrast agents that are already close to moving to the clinic, we think that this strategy is shortsighted and hinders the future potential of what can be achieved with advances in the chemistry relevant to contrast agents. We look forward to following great chemical, biological, and clinical advances in the field over the next $30+$ years.

\section{References}

1. Weinmann HJ, Brasch RC, Press WR, Wesbey GE (1984) AJR Am J Roentgenol 142:619-624

2. Gries H, Rosenberg D, Weinmann HJ (1981) German Patent DEOS 3129906
3. Fobben E, Wolf GL (1983) Invest Radiol 18:S5

4. Gries H, Rosenberg D, Weinmann HJ (1984) US Patent $4,647,447$

5. Joint Meeting of the FDA Cardiovascular and Renal Drugs and Drug Safety and Risk Management Advisory Committee; Gaithersburg, 8 Dec 2009. http://www.fda.gov/AdvisoryCommittees/ CommitteesMeetingMaterials/Drugs/CardiovascularandRenalDrugs AdvisoryCommittee/ucm196216.htm. Accessed 1 Aug 2013

6. Cacheris WP, Quay SC, Rocklage SM (1990) Magn Reson Imaging 8:467-481

7. Wedeking P, Kumar K, Tweedle MF (1992) Magn Reson Imaging 10:641-648

8. Idee JM, Port M, Raynal I, Schaefer M, Le Greneur S, Corot C (2006) Fundam Clin Pharmacol 20:563-576

9. Sherry AD, Caravan P, Lenkinski RE (2009) J Magn Reson Imaging 30:1240-1248

10. Grobner T (2006) Nephrol Dial Transplant 21:1104-1108

11. Swaminathan S, High WA, Ranville J, Horn TD, Hiatt K, Thomas M, Brown HH, Shah SV (2008) Kidney Int 73:1413-1418

12. Frenzel T, Lengsfeld P, Schirmer H, Hutter J, Weinmann HJ (2008) Invest Radiol 43:817-828

13. Thomsen HS (2009) Radiol Clin North Am 47:827

14. Yang L, Krefting I, Gorovets A, Marzella L, Kaiser J, Boucher R, Rieves D (2012) Radiology 265:248-253

15. Wang YB, Alkasab TK, Narin O, Nazarian RM, Kaewlai R, Kay J, Abujudeh HH (2011) Radiology 260:105-111

16. Bloembergen N, Purcell EM, Pound RV (1948) Phys Rev 73:679-712

17. Solomon I (1955) Phys Rev 99:559-565

18. Bloembergen N (1957) J Chem Phys 27:572-573

19. Bloembergen N, Morgan LO (1961) J Chem Phys 34:842-850

20. Lauffer RB, Brady TJ, Brown RD, Baglin C, Koenig SH (1986) Magn Reson Med 3:541-548

21. Lauffer RB, Brady TJ (1985) Magn Reson Imaging 3:11-16

22. Southwood-Jones RV, Earl WL, Newman KE, Merbach AE (1980) J Chem Phys 73:5909-5918

23. Helm L, Merbach AE (1999) Coord Chem Rev 187:151-181

24. Nicolle GM, Toth E, Schmitt-Willich H, Raduchel B, Merbach AE (2002) Chem Eur J 8:1040-1048

25. Wiener EC, Brechbiel MW, Brothers H, Magin RL, Gansow OA, Tomalia DA, Lauterbur PC (1994) Magn Reson Med 31:1-8

26. Tóth E, Pubanz D, Vauthey S, Helm L, Merbach AE (1996) Chem Eur J 2:1607-1615

27. Pierre VC, Botta M, Raymond KN (2004) J Am Chem Soc 127:504-505

28. Dumas S, Jacques V, Sun WC, Troughton JS, Welch JT, Chasse JM, Schmitt-Willich H, Caravan P (2010) Invest Radiol 45:600-612

29. Jacques V, Dumas S, Sun WC, Troughton JS, Greenfield MT, Caravan P (2010) Invest Radiol 45:613-624

30. Raymond KN, Pierre VC (2004) Bioconjug Chem 16:3-8

31. Lebduskova P, Hermann P, Helm L, Toth E, Kotek J, Binnemans K, Rudovsky J, Lukes I, Merbach AE (2007) Dalton Trans 493-501

32. Laus S, Ruloff R, Tóth É, Merbach AE (2003) Chem Eur J 9:3555-3566

33. Aime S, Barge A, Bruce JI, Botta M, Howard JAK, Moloney JM, Parker D, de Sousa AS, Woods M (1999) J Am Chem Soc 121:5762-5771

34. Zhang SR, Winter P, Wu KC, Sherry AD (2001) J Am Chem Soc 123:1517-1518

35. Aime S, Barge A, Delli Castelli D, Fedeli F, Mortillaro A, Nielsen FU, Terreno E (2002) Magn Reson Med 47:639-648

36. Molecular Imaging and Contrast Agent Database (MICAD) (2004-2013). National Center for Biotechnology Information, Bethesda. http://www.ncbi.nlm.nih.gov/books/NBK5330/ 
37. MedicineNet (1999) Drug approvals - from invention to market ... a 12- year trip. http://www.medicinenet.com/script/main/art. asp?articlekey=9877. Accessed 8 Aug 2013

38. Botta M, Gambino G, De Pinto S, Tei L, Cassino C, Arena F, Gianolio E (2014) J Biol Inorg Chem. doi:10.1007/s00775-0131050-0

39. Jaccard H, Miéville P, Cannizzo C, Mayer CR, Helm L (2014) J Biol Inorg Chem. doi:10.1007/s00775-013-1036-y

40. Garcia J, Neelavalli J, Haacke EM, Allen MJ (2011) Chem Commun 47:12858-12860

41. Sherry A, Mani T, Opina AC, Zhao P, Evbuomwan O, Milburn N, Tircso G, Kumas C (2014) J Biol Inorg Chem. doi:10.1007/ s00775-013-1031-3

42. Slack J, Woods M et al (2014) J Biol Inorg Chem. doi:10.1007/ s00775-013-1060-y

43. Morrow J, Dorazio S, Olatunde A, Tsitovich P (2014) J Biol Inorg Chem. doi:10.1007/s00775-013-1059-4

44. Aime S, Castelli D, Boffa C, Giustetto P, Terreno E (2014) J Biol Inorg Chem. doi:10.1007/s00775-013-1042-0
45. Parker D, Harvey P, Chalmers K, Mishra A, Senanayake K, Wilson I, Blamire A, Botta M, Fekete M (2014) J Biol Inorg Chem. doi:10.1007/s00775-013-1028-y

46. Zhang X-a, Cheng W, Ganesh T, Martinez F, Lam J, Yoon H, Macgregor R, Scholl T, Cheng H-L (2014) J Biol Inorg Chem. doi:10.1007/s00775-013-1073-6

47. Qazi S, Uchida M, Usselman R, Shearer R, Edwards E, Douglas T (2014) J Biol Inorg Chem. doi:10.1007/s00775-013-1075-4

48. Smolensky ED, Neary MC, Zhou Y, Berquo TS, Pierre VC (2011) Chem Commun 47:2149-2151

49. Tu C, Ng TC, Jacobs RE, Louie AY (2014) J Biol Inorg Chem. doi:10.1007/s00775-013-1054-9

50. Qiao J, Xue S, Pu F, White N, Jiang J, Liu Z-R, Yang JY (2014) J Biol Inorg Chem. doi:10.1007/s00775-013-1076-3

51. Kodibagkar V, Gulaka P, Rojas-Quijano F, Kovacs Z, Mason R, Sherry A, Mason R (2014) J Biol Inorg Chem. doi:10.1007/ s00775-013-1058-5

52. Martins AF, Morfin J-F, Geraldes CFGC, Tóth É (2014) J Biol Inorg Chem. doi:10.1007/s00775-013-1055-8 